Research Paper

\title{
Influence of carvacrol and thymol on the physiological attributes, enterotoxin production and surface characteristics of Staphylococcus aureus strains isolated from foods
}

\author{
E.L. Souza ${ }^{1}$, C.E.V. Oliveira ${ }^{1}$, T.L.M. Stamford ${ }^{2}$, M.L. Conceição ${ }^{1}$, N.J. Gomes Neto ${ }^{1}$ \\ ${ }^{1}$ Laboratório de Microbiologia de Alimentos, Departamento de Nutrição, Centro de Ciências da Saúde, \\ Universidade Federal da Paraíba, João Pessoa, PB, Brazil. \\ ${ }^{2}$ Laboratório de Microbiologia de Alimentos, Departamento de Nutrição, Centro de Ciências da Saúde, \\ Universidade Federal de Pernambuco, Recife, PE, Brazil.
}

Submitted: April 16, 2011; Approved: July 02, 2012.

\begin{abstract}
This study evaluated the influence of the phenolic compounds carvacrol (CAR) and thymol (THY) on some physiological characteristics and on the modulation of the secretion of some staphylococcal virulence factors, that is, coagulase and enterotoxin. This study also investigated possible mechanisms for the establishment of the anti-staphylococcal activity of these compounds. Sublethal concentrations ( 0.3 and $0.15 \mu \mathrm{L} / \mathrm{mL})$ of CAR and THY inhibited the activity of the enzymes coagulase and lipase and led to a decrease in salt tolerance. At the tested sublethal concentrations, both CAR and THY led to a total suppression of enterotoxin production. The loss of a 260 -nm-absorbing material and an efflux of potassium ions occurred immediately after the addition of CAR and THY at 0.6 and $1.2 \mu \mathrm{L} / \mathrm{mL}$ and increased up to $120 \mathrm{~min}$ of exposure. Electron microscopy of cells exposed to CAR and THY $(0.6 \mu \mathrm{L} / \mathrm{mL})$ revealed that individual cells appeared to be deformed, with projections of cellular material. The observations of leakage of cellular material and an altered cell surface suggest that gross damage to a cell's cytoplasmic membrane, which results in a disruption in protein secretion, could be responsible for the anti-staphylococcal properties of CAR and THY.
\end{abstract}

Key words: phenolic compounds, physiological suppression, staphylococcal enterotoxins, virulence.

\section{Introduction}

Staphylococcus aureus is a common pathogen that is associated with serious community and nosocomial infections and is known as major cause of food poisoning due to the production of enterotoxins (Pereira et al., 2009). The occurrence of $S$. aureus toxicity depends on the capability of the strain to survive, multiply under a variety of conditions and produce extracellular toxic compounds. Hemolysins, nuclease, coagulase, lipase and enterotoxins are among the extracellular toxins and enzymes produced by $S$. aureus (Shae et al., 2005).

Staphylococcal enterotoxins (SEs) comprise a group of heat stable and serologically diverse proteins. Twenty different types of SEs, i.e., SEA-SEE, SEG-SER and SEU, have already been discovered; however, SEA-SEEs are the most common enterotoxins involved in staphylococcal food poisoning (Jørgensen et al., 2005).

Because staphylococcal foodborne intoxication represents a public health problem worldwide, the development of strategies to control the survival and growth of $S$. aureus in foods is of great interest (Barros et al., 2009). Particularly, the increased demand for safe and natural foods has motivated researchers to investigate the antimicrobial efficacies of many natural compounds against food-related pathogenic microorganisms (Bento et al., 2009). The current trend of a negative consumer perception of chemical preservatives has prompted a particularly increased interest in the use of essential oils as antimicrobial compounds in

Send correspondence to E.L. Souza. Departamento de Nutrição, Centro de Ciências da Saúde, Universidade Federal da Paraíba, Campus I, Cidade Universitária, 58051-900 João Pessoa, PB, Brazil. E-mail: evandroleitesouza@ccs.ufpb.br. 
food preservation (Souza et al., 2007; Gutierrez et al., 2008).

The essential oil of Origanum vulgare L. (OVEO), popularly known as oregano, has been found to antagonize several food-related bacteria (Nostro et al., 2004; Souza et al., 2006). An early study focusing on the antimicrobial properties of OVEO found that this substance strongly inhibits the growth and some of the metabolic characteristics of food-isolated $S$. aureus strains, including coagulase and lipase activities and salt tolerance (Barros et al., 2009). Some researchers have reported a high content of phenolic compounds in OVEO, mostly carvacrol (CAR) and thymol (THY), which are most likely responsible for the prominent antimicrobial effects (Rhayour et al., 2003; Burt, 2004).

Although previous researchers have described the antimicrobial activities of CAR and THY against foodrelated microorganisms (Lambert et al., 2001; Ultee et al., 2002), there is a lack of information about their effect on the physiological characteristics, including some virulence attributes, of S. aureus. The aim of this study was to verify whether sublethal concentrations of the phenolic compounds CAR and THY, the major components of OVEO, exert an influence on some of the physiological characteristics, including enterotoxin production, of $S$. aureus strains isolated from foods and to investigate the possible mechanisms for the establishment of the anti-staphylococcal activities of these compounds.

\section{Methods}

\section{Test organisms}

S. aureus QCD, S. aureus QCE and S. aureus QCF, which were obtained from the Microorganism Collection, Laboratory of Food Microbiology, Health Sciences Center, Federal University of Paraíba (João Pessoa, Brazil), were used as test microorganisms. These strains were isolated from different unripened cheese samples using standard procedures (Bennet et al., 1986; Vnaderzant and Splittstoesser, 1992). Stock cultures were maintained on Nutrient Agar - NA (Sigma, France) slants under refrigeration $\left(7 \pm 1^{\circ} \mathrm{C}\right)$ conditions.

The inocula used in the assays were obtained from cultures grown overnight on NA slants $\left(37^{\circ} \mathrm{C}\right)$. A loopful of the culture was diluted in a sterile saline solution $(0.85 \mathrm{~g} / 100 \mathrm{~mL})$ to obtain a final concentration of approximately $10^{8}$ colony forming units per $\mathrm{mL}(\mathrm{cfu} / \mathrm{mL})$ adjusted to the turbidity of a $0.5 \mathrm{McF}$ arland standard tube.

\section{Phenolic compounds}

The phenolic compounds, CAR and THY, were supplied by Sigma Aldrich (Sigma, France). Stock solutions were prepared in Nutrient Broth - NB (Sigma, France) using bacteriological agar $(0.15 \mathrm{~g} / 100 \mathrm{~mL})$ as a stabilizing agent (Bennis et al., 2004). Using the test strains included in this study, previous studies found values for minimum inhibitory concentrations and minimum bactericidal concentrations of 0.6 and $1.2 \mu \mathrm{L} / \mathrm{mL}$, respectively, for both CAR and THY (Oliveira et al., 2010).

\section{Assays for enzymatic activities and salt tolerance}

Lipase activity was estimated using Agar Salty Tween - AST (Nostro et al., 2001a), which contained: (g/L) peptone 10.0; $\mathrm{NaCl} 75.0 ; \mathrm{CaCl}_{2} \mathrm{H}_{2} \mathrm{O}$ 0.10; Tween 8010 $(\mathrm{pH}$ 7.2). Bacterial inocula $(100 \mu \mathrm{L})$ grown overnight in NB $\left(37^{\circ} \mathrm{C}\right)$ and diluted $\left(10^{-1}-10^{-4}\right)$ in sterile peptone water $(0.1 \mathrm{~g} / 100 \mathrm{~mL})$ were plated onto AST. Sublethal concentrations of CAR or THY $(0.3$ and $0.15 \mu \mathrm{L} / \mathrm{mL})$ were then added to the AST followed by incubation at $37{ }^{\circ} \mathrm{C}$ for $24 \mathrm{~h}$. After the incubation period, the number of lipase positive colonies $(\mathrm{cfu} / \mathrm{mL})$ on each AST plate was counted and compared to the number of positive colonies found on AST supplemented with CAR and THY. The results are expressed as a percentage of the inhibition of the lipase activity.

For testing coagulase activity, a $100 \mu \mathrm{L}$ aliquot of inoculum (approximately $10^{7} \mathrm{cfu} / \mathrm{mL}$ ) was transferred to Brain Heart Infusion - BHI (Sigma, France) broth supplemented with sublethal concentrations of CAR or THY $(0.3$ and $0.15 \mu \mathrm{L} / \mathrm{mL}$ ) and incubated at $37^{\circ} \mathrm{C}$ for $24 \mathrm{~h}$. After the incubation period, coagulase activity (a tube coagulase test) was determined using a standard procedure (Walsh et al., 2003), and the results were expressed based on the size (-; + to ++++ ) of the formed plasma clot [free coagulase forms thrombin, which converts fibrinogen to fibrin and results in plasma clotting (observed after $4 \mathrm{~h}$ of incubation at $37^{\circ} \mathrm{C}$ )]. Tubes lacking CAR or THY were treated similarly to the positive control.

Preliminary experiments were performed to evaluate the salt tolerance of the strains. For these experiments, $100 \mu \mathrm{L}$ aliquots of the cultures were spread-plated onto sterile NA and NA supplemented with $\mathrm{NaCl}$ (5 to $100 \mathrm{~g} / \mathrm{L}$; $\mathrm{NA}-\mathrm{NaCl}$ ) to determine the $\mathrm{NaCl}$ concentration that modestly inhibited the colony-forming ability of the cultures. Suspensions of bacteria were exposed overnight to sublethal concentrations of CAR or THY ( 0.3 and $0.15 \mu \mathrm{L} / \mathrm{mL})$ in $\mathrm{NB}\left(37^{\circ} \mathrm{C}\right)$. Next, $100 \mu \mathrm{L}$ of culture was diluted $\left(10^{-1}-10^{-4}\right)$ with sterile peptone water $(0.1 \mathrm{~g} / 100 \mathrm{~mL})$ and plated onto $\mathrm{NA}-\mathrm{NaCl}$ at $37^{\circ} \mathrm{C}$ for $24 \mathrm{~h}$ (Carson et al., 2002). Control tubes lacking CAR or THY were similarly treated. After the incubation period, the number of $\mathrm{cfu} / \mathrm{mL}$ for each NA-NaCl plate was compared to that found for the control assay, and the results are expressed as the percentage of cells able to form colonies.

\section{Assay for enterotoxin production}

The production of staphylococcal enterotoxins by $S$. aureus QCF was estimated using an immunological assay, the VIDAS Staph Enterotoxin II (SET2) kit (BioMérieux, Marcy L'étoile, France) and the Mini VIDAS apparatus - 
AOAC RI N ${ }^{\circ} 070404$. For this assay, a loopful of an overnight NB culture $\left(37^{\circ} \mathrm{C}\right)$ was suspended in BHI broth supplemented with sublethal concentrations of CAR or THY ( 0.3 and $0.15 \mu \mathrm{L} / \mathrm{mL}$ ) and incubated for $18 \mathrm{~h}$ under static conditions at $37^{\circ} \mathrm{C}$ (Oliveira et al., 2010). After the incubation period, the growth media was centrifuged $(3000 \mathrm{~g}$, $4{ }^{\circ} \mathrm{C}$ ), and an aliquot of the supernatant was taken and submitted to an enterotoxin detection test according to procedures described by the manufacturer. The results are expressed in terms of positive $(+)$ and (-) negative enterotoxin production. Tubes lacking CAR or THY were treated similarly to the positive control assay.

\section{Assay for potassium ion efflux}

The potassium ion concentration in a cell suspension of $S$. aureus QCF was measured after exposure to CAR or THY $(0.3$ and $0.6 \mu \mathrm{L} / \mathrm{mL})$ in sterile peptone water $(0.1$ $\mathrm{g} / 100 \mathrm{~mL}$ ) for $0,30,60$ and $120 \mathrm{~min}$. At each preestablished interval, the extracellular potassium concentration was measured using a photometric procedure and a potassium kit (Human GmbH, Wiesbaden, Germany) (Oliveira et al., 2010). Control flasks lacking CAR or THY were treated similarly. The results are expressed as the amount of extracellular free potassium $(\mathrm{mmol} / \mathrm{L})$ in the growth medium at each interval of the incubation.

\section{Release of cellular material}

The release of cellular material absorbing at $260 \mathrm{~nm}$ from $S$. aureus QCF was determined in $2 \mathrm{~mL}$ aliquots of bacterial inocula containing approximately $10^{8} \mathrm{cfu} / \mathrm{mL}$ in sterile peptone water $(0.1 \mathrm{~g} / 100 \mathrm{~mL})$ supplemented with CAR or THY $(0.3$ and $0.6 \mu \mathrm{L} / \mathrm{mL})$ at $37^{\circ} \mathrm{C}$. After $0,30,60$ and $120 \mathrm{~min}$ of treatment, the cells were centrifuged $\left(3000 \mathrm{~g}, 4^{\circ} \mathrm{C}\right)$, and the absorbance $(260 \mathrm{~nm})$ of the obtained supernatant was determined using a Biochrom Libra S32/S32 spectrophotometer (Carson et al., 2002). Control flasks lacking CAR or THY were treated similarly. The results are expressed as the percent of the material absorbing at $260 \mathrm{~nm}$ in each interval with respect to the last time interval.

The assays for lipase activity, salt tolerance, potassium ion efflux and release of cellular material were performed in triplicate on three separate occasions, and the results are expressed as averages for each of the assays. The assays for coagulase activity were performed in triplicate on three separate occasions with consistent results.

\section{Cell morphology using scanning electronic microscopy}

After an overnight exposure of $S$. aureus QCF to CAR or THY $(6 \mu \mathrm{L} / \mathrm{mL})$ in BHI broth at $37^{\circ} \mathrm{C}$, the bacterial cells were pre-fixed with glutaraldehyde $(2 \mathrm{~mL} / 100 \mathrm{~mL})$ for $2 \mathrm{~h}$ at $4{ }^{\circ} \mathrm{C}$ and postfixed using an osmium tetroxide solution $(1 \mathrm{~g} / 100 \mathrm{~mL})$ for $30 \mathrm{~min}$ at $30^{\circ} \mathrm{C}$. After each fixation, the cells were washed twice with PBS. The cells were then dried at a critical point in liquid $\mathrm{CO}_{2}$ and gold covered by cathodic spraying (fine coat ion sputter JFC-1100, JEOL Ltd., Tokyo, Japan). Finally, the cells were examined using a scanning electron microscope (JEOL JSM-5600 LV, PAIS) as previously described (Bennis et al., 2004). Cells not exposed to CAR and THY were submitted to the same procedures as described for the controls.

\section{Results}

The proportion of $S$. aureus cells presenting lipase negative colonies after exposure to sublethal concentrations of CAR or THY was monitored (Table 1). Incubation of the cultures with sublethal concentrations of both tested phenolic compounds revealed a strong inhibition of lipase activity. CAR or THY at 0.3 and $0.15 \mu \mathrm{L} / \mathrm{mL}$ provided an inhibition of lipase activity of over $50 \%$ with all test strains.

The effect of CAR and THY on the coagulase activity of $S$. aureus cells is shown in Table 2 . At $0.3 \mu \mathrm{L} / \mathrm{mL}$, the phenolic compounds led to a large reduction in coagulase activity, that is, no clotting was evident after incubating the cultures in the presence of rabbit plasma. When CAR or THY was added to the growth medium at $0.15 \mu \mathrm{L} / \mathrm{mL}$, a less significant reducing effect was noted in cells, that is, ++ (level 2) or +++ (level 3) levels of coagulase activity.

The growth of $S$. aureus cells exposed to CAR or THY in salt-supplemented agar was assessed to verify the influence of these compounds on salt tolerance (Table 3). The addition of sublethal concentrations of CAR or THY clearly reduced the colony-forming ability of the cells in the selective medium. Exposure to CAR or THY at $0.3 \mu \mathrm{L} / \mathrm{mL}$ totally suppressed the capability of the cells to form colonies on NA-NaCl. At the lower concentration $(0.15 \mu \mathrm{L} / \mathrm{mL})$, the tested phenolic compounds also led to a

Table 1 - Proportion of S. aureus cells presenting lipase negative colonies on Salty Tween agar (STA) and Salty Tween agar supplemented with CAR or THY at sublethal concentrations.

\begin{tabular}{lcccccc}
\hline \multirow{2}{*}{ Strains } & \multirow{2}{*}{ AST } & \multicolumn{2}{c}{ AST-CAR } & & \multicolumn{2}{c}{ AST-THY } \\
\cline { 3 - 4 } \cline { 6 - 7 } & & $0.3 \mu \mathrm{L} / \mathrm{mL}$ & $0.15 \mu \mathrm{L} / \mathrm{mL}$ & & $0.3 \mu \mathrm{L} / \mathrm{mL}$ & $0.15 \mu \mathrm{L} / \mathrm{mL}$ \\
\hline S. aureus $\mathrm{QCD}$ & $0 \% *$ & $50 \%$ & $48 \%$ & & $50 \%$ & $49 \%$ \\
S. aureus $\mathrm{QCE}$ & $0 \% *$ & $51 \%$ & $49 \%$ & & $52 \%$ & $50 \%$ \\
S. aureus $\mathrm{QCF}$ & $0 \% *$ & $51 \%$ & $49 \%$ & & $51 \%$ & $49 \%$ \\
\hline
\end{tabular}


Table 2 - Effect of sublethal concentrations of CAR or THY on the coagulase activities of the S. aureus strains.

\begin{tabular}{lcccccc}
\hline Strains & Control & \multicolumn{2}{c}{ CAR } & & \multicolumn{2}{c}{ THY } \\
\cline { 3 - 4 } \cline { 6 - 7 } & & $0.3 \mu \mathrm{L} / \mathrm{mL}$ & $0.15 \mu \mathrm{L} / \mathrm{mL}$ & & $0.3 \mu \mathrm{L} / \mathrm{mL}$ & $0.15 \mu \mathrm{L} / \mathrm{mL}$ \\
\hline S. aureus QCD & ++++ & - & ++ & & - & +++ \\
S. aureus QCE & ++++ & - & ++ & & - & +++ \\
S. aureus QCF & ++++ & - & ++ & & - & ++ \\
\hline
\end{tabular}

CAR: carvacrol; THY: thymol.

Table 3 - Proportion of S. aureus cells able to form colonies on NA supplemented with $75 \mathrm{~g} \mathrm{NaCl} / \mathrm{L}$ (NA-NaCl) after exposure to CAR or THY at sublethal concentrations.

\begin{tabular}{lcccccc}
\hline \multirow{2}{*}{ Strains } & Control & \multicolumn{2}{c}{ CAR } & & \multicolumn{2}{c}{ THY } \\
\cline { 3 - 4 } \cline { 6 - 7 } & & $0.3 \mu \mathrm{L} / \mathrm{mL}$ & $0.15 \mu \mathrm{L} / \mathrm{mL}$ & & $0.3 \mu \mathrm{L} / \mathrm{mL}$ & $0.15 \mu \mathrm{L} / \mathrm{mL}$ \\
\hline S. aureus QCD & $100 \%$ & $0 \%$ & $12 \%$ & & $0 \%$ & $10 \%$ \\
S. aureus QCE & $100 \%$ & $0 \%$ & $8 \%$ & & $0 \%$ & $11 \%$ \\
S. aureus QCF & $100 \%$ & $0 \%$ & $9 \%$ & & $0 \%$ & $16 \%$ \\
\hline
\end{tabular}

CAR: carvacrol; THY: thymol; AST-C: Agar Salt-Tween supplemented with CAR; AST-T: Agar Salt-Tween supplemented with THY.

reduction in colony formation on $\mathrm{NA}-\mathrm{NaCl}$. However, the reduction was to a lesser extent (8-16\%).

The influence of CAR and THY at sublethal concentrations on the enterotoxin production of $S$. aureus QCF was evaluated. Early assays showed that $S$. aureus QCF presented a greater capability to produce enterotoxins in comparison to the other strains included in this study. Cultures of $S$. aureus QCF that grew in the presence of CAR or THY at both tested concentrations exhibited a total inhibition of enterotoxin production.

In an attempt to elucidate the cause of the anti-staphylococcal effect, the loss of 260-nm-absorbing material and the release of potassium ions from cells exposed to CAR or THY at 0.3 and $0.6 \mu \mathrm{L} / \mathrm{mL}$ was evaluated (Table 4 and Figure 1). The $\mathrm{OD}_{260 \mathrm{~nm}}$ of the $S$. aureus QCF cell filtrates exposed to CAR or THY displayed increasing values during the evaluated times. The efflux of potassium ions from the $S$. aureus cells occurred immediately after the addition of the tested phenolic compounds and followed a steady increasing release during the evaluated intervals. CAR pro-

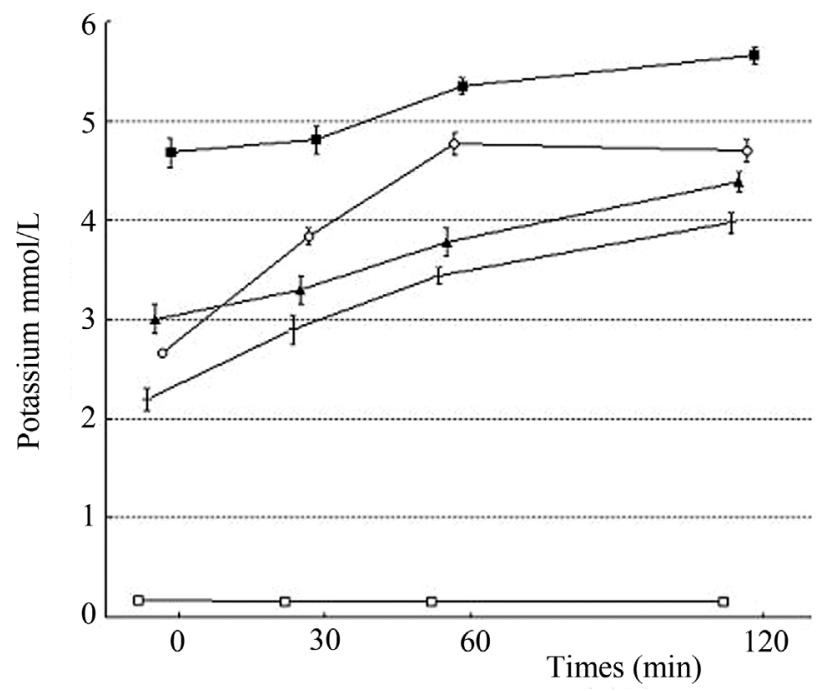

Figure 1 - Leakage of potassium ions from $S$. aureus $\mathrm{QCF}$ cells induced by exposure to carvacrol (CAR) and thymol (THY) for $120 \mathrm{~min}$ at $37^{\circ} \mathrm{C}$ ( $\square$ : control, $0 \mu \mathrm{L} / \mathrm{mL}$; +: THY, $0.6 \mu \mathrm{L} / \mathrm{mL} ; \mathbf{\Delta}$ : THY, $0.12 \mu \mathrm{L} / \mathrm{mL}$; O: CAR, $0.6 \mu \mathrm{L} / \mathrm{mL} ; \mathbf{\square}: 0.12 \mu \mathrm{L} / \mathrm{mL}$ ).

Table 4 - Rate of release of 260-nm-absorbing material from S. aureus QCF cells exposed to CAR or THY.

\begin{tabular}{|c|c|c|c|c|}
\hline \multirow[t]{2}{*}{ Time (min) } & \multicolumn{2}{|c|}{ CAR } & \multicolumn{2}{|c|}{ THY } \\
\hline & $\begin{array}{c}0.3 \mu \mathrm{L} / \mathrm{mL} \\
\mathrm{A} 260(\%)\end{array}$ & $\begin{array}{r}0.6 \mu \mathrm{L} / \mathrm{mL} \\
\text { A260 (\%) }\end{array}$ & $\begin{array}{r}0.3 \mu \mathrm{L} / \mathrm{mL} \\
\mathrm{A} 260(\%)\end{array}$ & $\begin{array}{r}0.6 \mu \mathrm{L} / \mathrm{mL} \\
\mathrm{A} 260(\%)\end{array}$ \\
\hline 0 & 66.01 & 93.48 & 36.87 & 40.67 \\
\hline 30 & 88.71 & 98.49 & 61.11 & 57.09 \\
\hline 60 & 89.30 & 100 & 66.56 & 69.45 \\
\hline 120 & 100 & 100 & 100 & 100 \\
\hline
\end{tabular}

CAR: carvacrol; THY: thymol; AST-CAR: Agar Salt-Tween supplemented with CAR; AST-THY: Agar Salt-Tween supplemented with THY; * All colonies grown in AST were lipase positive. 
vided a higher loss of 260-nm-absorbing material and leakage of potassium ions in comparison to THY. No leakage of potassium ions was observed when $S$. aureus was grown in media lacking CAR or THY. These results indicate that increased membrane permeability is a factor involved in the establishment of the anti-staphylococcal property of the tested compounds.

With regards to the fact that the assayed phenolic compounds led to a release of cellular compounds from $S$. aureus $\mathrm{QCF}$, the effect of CAR and THY on the bacterial surface cells was investigated. The scanning electron microphotographs showed some morphological damage after exposure to CAR or THY $(6 \mu \mathrm{L} / \mathrm{mL})$. The damage caused by CAR (Figure 2a) appeared to be greater than that caused by THY (Figure 2b). Although some background cells did not present alterations, it might be that the surfaces of some cells were consistently deformed, which would reveal the appearance of cellular materials. Cells not exposed to CAR and THY displayed no alterations in cell surface morphology (Figure 2c). These findings suggest that both tested compounds could exert their anti-staphylococcal activities by damaging the bacterial cell envelope.

\section{Discussion}

The effect of the phenolic compounds CAR and THY on some of the physiological characteristics and morphological aspects of $S$. aureus strains isolated from foods was described. It is clear that the assayed compounds strongly interfered with the physiological characteristics, such as cytoplasmic membrane permeability, coagulase activity, salt tolerance and enterotoxin production, of the test strains.

Coagulase and lipase assays revealed that CAR and THY suppressed these enzymatic activities in S. aureus and inhibited its production of staphylococcal enterotoxins. Such phenotypic modifications might possibly arise as a result of interactions between the phenolic compounds and enzymes (Nostro et al., 2002). The reductions in the enzymatic activities (lipase and coagulase) of the cells and in the synthesis of enterotoxins most likely occurred due to a prevention of protein secretion, which could have been a consequence of changes in the physical nature of the staphylococcal cytoplasmic membrane (Nostro et al., 2002; Shah et al., 2008). Still, it has been reported that the intercalation of active plant compounds into the cytoplasmic membrane may interfere with the process of membraneassociated signal transduction and impair the function of some membrane proteins, resulting in changes to the architecture and composition of the cell wall (Okubo et al., 1989; Ikigai et al., 1990; Gustafson et al., 1998).

Virulence expression in $S$. aureus is cited as controlled by complex regulatory networks, including twocomponent systems (e.g., AgrAC, SrrAB and SaeRAS) and transcription factors (e.g., SarA and its homologues) (Cheung et al., 2004; Even et al., 2009). Among these regu-
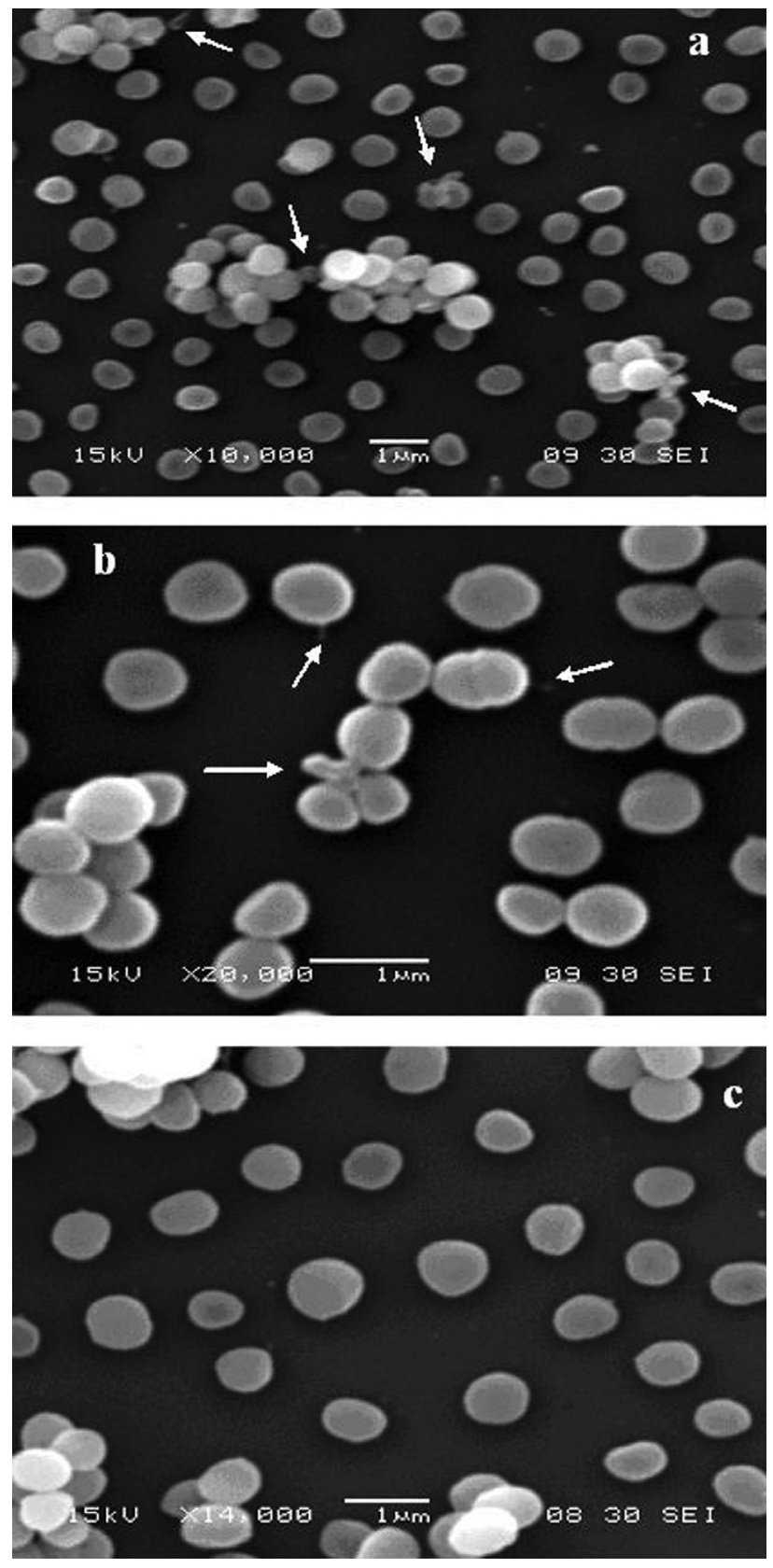

Figure 2 - Scanning electron microphotograph of S. aureus QCF cells after exposure to carvacrol (CAR) and thymol (THY). (a) CAR, $6 \mu \mathrm{L} / \mathrm{mL}$; (b) THY, $6 \mu \mathrm{L} / \mathrm{mL}$; (c) control, $0 \mu \mathrm{L} / \mathrm{mL}$. Different magnifications were used for better visualization.

latory systems, the accessory regulator gene $a g r$ is a central element in the modulation of virulence gene expression and is responsible for the post-exponential phase induction of extracellular enzymes and enterotoxins (Novick, 2003; Gao and Stewart, 2004). With regards to the results found in this study and that the activity of $a g r$ itself can be modulated in response to different stresses or environmental modifications (Nouaille et al., 2009), CAR and THY may possibly affect the $a g r$ system and impair the expression of several virulence genes with a downregulation of exoprotein production in S. aureus; however, the effects of es- 
sential oils and their related compounds toward S. aureus remains to be studied.

When tested at sublethal concentrations, some plant products may interfere with the secretion of virulence factors in bacteria. Helichrysum italicum extract is effective in inhibiting the enterotoxin production (SEB and SEC) and coagulase and lipase activities of S. aureus cells (Nostro et al., 2001a; Nostro et al., 2002). Likewise, the extract of Nepeta cataria leads to a suppression of these enzymatic activities in a number of $S$. aureus strains (Nostro et al., 2001b). The extract of Punica granatum was found to inhibit staphylococcal enterotoxin (SEA) production (Braga et al., 2005).

Sublethal injury of the bacterial cell membrane may interfere with permeability and affect the capability of the cell to adequately osmoregulate or to exclude toxic materials (Carson et al., 2002; Barros et al., 2009). The exposure of $S$. aureus cells to CAR or THY strongly reduced the capability of the cells to form colonies on selective media supplemented with salt. A decrease in salt tolerance has been cited as suggesting membrane damage in sublethally injured bacterial cells (Iandolo and Ordal, 1966). These observations are in accordance with the results for the release of 260-nm-absorbing material and the leakage of potassium ions because the addition of CAR or THY to the growth media led to a rapid release of cellular material.

A marked leakage of 260-nm-absorbing material and potassium ions is used as an indication of gross and irreversible damage to the cytoplasmic membrane (Walsh et al., 2003). A significant release of 260 -nm-absorbing material has also been reported as suggesting a loss of nucleic acid through a damaged cytoplasmic membrane (Carson et al., 2002). Some essential oils and their related compounds induce the leakage of 260-nm-absorbing material (Cox et al., 2000; Cox et al., 2001; Bennis et al., 2004).

As expected, the electron microscopy micrographs indicated significant damage to $S$. aureus cells exposed to CAR or THY. Although background cells did not display apparent surface alterations, the surfaces of some of the individual cells appeared to be deformed, resulting in projections of cellular material. Furthermore, the scanning electron microscopy observations suggest that CAR and THY led to membrane damage, which was accompanied by important surface alterations to the $S$. aureus cells. These antimicrobial mechanisms could also affect the entire envelope of the bacterial cell. Structures such as blebs on the outside surface of cells exposed to CAR or THY may represent a collection of cytoplasmic constituents that were pushed through cracks produced in the cell wall. Our results, which suggest a significant release of OD 260-nmabsorbing material, reinforce this idea. Similar observations have been previously described in Escherichia coli, Bacillus cereus and Saccharomyces cereviseae (Rhayour et al., 2003; Bennis et al., 2004).
Membrane-active compounds are cited as denaturing proteins and as disruptive to membrane structures, leading to cytoplasm leakage, cell lysis and death (Lambert et al., 2001). Earlier studies have revealed that phytochemicals, including phenolic compounds, are able to disrupt and penetrate into lipid structures (Rhayour et al., 2003). These findings have reinforced the hypothesis that these compounds inhibit microbial viability in a manner similar to membrane-active disinfectants (Even et al., 2009).

In addition to inhibiting the growth and survival of pathogenic bacteria in foods, new antimicrobials with the capability to inhibit the secretion of virulence attributes could be effective in decreasing the occurrence of foodborne diseases. Our results indicate that CAR and THY strongly interfere with some of the physiological characteristics of $S$. aureus, including suppressing enterotoxin production at sublethal concentrations. The observations of a release of cellular material and an altered cell surface morphology suggest that gross damage to a cell's cytoplasmic membrane could be responsible for the establishment of the anti-staphylococcal effects of CAR and THY. These findings indicate that further investigations are required for evaluating the antimicrobial properties of phenolic compounds and their influence on the metabolic characteristics of other foodborne pathogenic microorganisms.

\section{Acknowledgments}

The authors thank the CNPq (Conselho Nacional de Desenvolvimento Científico, Brazil) for their financial support.

\section{References}

Barros JC, Conceição ML, Gomes-Neto NJ, Costa ACV, Siqueira-Júnior JP, Basílio- Júnior ID, Souza EL (2009) Interference of Origanum vulgare L. essential oil on the growth and some physiological characteristics of Staphylococcus aureus strains isolated from foods. Lebens Winsech u-Technol 42:1139-1143.

Bennett RW, Yeterian M, Smith W, Coles CM, Sassaman M, McClure FD (1986) Staphylococcus aureus identification characteristics and enterotoxigenicity. J Food Sci 51:13371339.

Bennis S, Chami F, Chami N, Bouchikhi T, Remma A (2004) Surface alteration of Saccharomyces cerevisae induced by thymol and eugenol. Lett Appl Microbiol 38:454-458.

Bento RA, Stamford TLM, Campos-Takaki GM, Stamford TCM, Souza EL (2009) Potential of chitosan from Mucor rouxii UCP064 as alternative natural compound to inhibit Listeria monocytogenes. Braz J Microbiol 40:583-589.

Braga LC, Shupp JW, Cumming C, Jett M, Takahashi JA, Carmo LS, Chartone-Souza E, Nascimento AMA (2005) Pomegrate extract inhibits Staphylococcus aureus growth and subsequent enterotoxins production. J Ethnopharmacol 96:335-339

Burt S (2004) Essential oils: their antibacterial properties and potential applications in foods - A review. Int J Food Microbiol 94:223-253. 
Carson CF, Mee BJ, Riley TV (2002) Mechanism of action of Melaleuca alternifolia (Tea tree) oil on Staphylococcus aureus determined by time-kill, lysis, leakage, and salt tolerance assay and electron microscopy. Antimicrob Agent Chemother 46:191-1920.

Cheung AL, Bayer AS, Zhang G, Gresham H, Xiong YQ (2004) Regulation of virulence determinants in vitro and in vivo Staphylococcus aureus. FEMS Immunol Med Microbiol 40:1-9.

Cox SD, Mann CM, Markhan JL, Bell HC, Gustafson JE, Warmington JR, Wyllie SG (2000) The mode of antimicrobial action of the essential oil of Melaleuca alternifolia (tea tree oil). J Appl Microbiol 88:170-175.

Cox SD, Mann CM, Markhan JL, Gustafson JE, Warmington JR, Wyllie SG (2001) Determining the antimicrobial action of tea tree oil. Molecules 6:87-91.

Even S, Charlier C, Nouaille S, Ben Zakour NL, Cretenet M, Cousin FJ, Gautier M, Cocaign-Bouquet M, Loubière P, Le Loir Y (2009) Staphylococcus aureus virulence expression is impaired by Lactococcus lactis in mixed cultures. Appl Environ Microbiol 75:4459-4472.

Gao J, Stewart GC (2004) Regulatory elements of the Staphylococcus protein A (Spa) promoter. J Bacteriol 186:37383748.

Gustafson JE, Liew YC, Chew S, Markhan J, Bell H, Wyllie HG, Warmington JR (1998) Effects of tea tree oil on Escherichia coli. Lett Appl Microbiol 26:194-198.

Gutierrez J, Barry-Ryan C, Bourke P (2008). The antimicrobial efficacy of plant essential oil combinations and interactions with food ingredients. Int J Food Microbiol 124:91-97.

Iandolo JJ, Ordal ZJ (1966) Repair of thermal injury of Staphylococcus aureus. J Bacteriol 91:134-142.

Ikigai H, Toda M, Okubo S, Hara Y, Shimamura T (1990) Relationship between the anti-haemolysin activity and the structure of catechins and theaflavins. Nippon Saikingaku Zasshi 45:913-919.

Jørgensen HJ, Mathisen T, Lovseth A, Omoe K, Qvale KS, Loncarevic S (2005) An outbreak of staphylococcal food poisoning caused by enterotoxin $\mathrm{H}$ in mashed potato made with raw milk. FEMS Microbiol Lett 252:267-272.

Lambert RJW, Skandamis PN, Coote P, Nychas GJE (2001) A study of the minimum inhibitory concentration and mode of action of oregano essential oil, thymol, and carvacrol. J Appl Microbiol 91:453-462.

Nostro A, Bisignano G, Cannatelli MA, Crisaf G, Germano MP, Alonzo V (2001a) Effects of Helichrysum italicum extract on growth and enzymatic activity of Staphylococcus aureus. Int J Antimicrob Agent 17:517-520.

Nostro A, Blanco AR, Cannatelli MA, Enea V, Flamini G, Morelli I, Roccaro AS, Alonzo V (2004) Susceptibility of methicillin-resistant staphylococci to oregano essential oil, carvacrol and thymol. FEMS Microbiol Lett 230:191-195.

Nostro A, Cannatelli MA, Crisafi G, Alonzo V (2001b) The effect of Nepeta cataria extract on adherence and enzyme produc- tion of Staphylococcus aureus. Int J Antimicrob Agent 18:583-555.

Nostro A, Cannatelli MA, Musolino AD, Procopio F, Alonzo V (2002) Helichrysum italicum extract interferes with the production of enterotoxins by Staphylococcus aureus. Lett Appl Microbiol 35:181-184.

Nouaille S, Even S, Charlier C, Le Loir Y, Cocaign-Bousquet M, Loubiére P (2009) Transcriptomic responses of Lactococcus lactis in mixed cultures with Staphylococcus aureus. Appl Environ Microbiol 75:4473-4482.

Novick RP (2003) Autoinduction and signal transduction in the regulation of staphylococcal virulence. Mol Microbiol 48:1429-1449.

Okubo S, Ikigai H, Toda M, Shimamura T (1989) The anti-haemolysin activity of tea and coffee. Lett Appl Microbiol 9:65-66

Oliveira CEV, Stamford TLM, Gomes-Neto NJ, Souza EL (2010) Inhibition of Staphylococcus aureus in broth and meat broth using synergies of phenolic compounds and organic acids. Int J Food Microbiol 137:312-316.

Pereira V, Lopes C, Castro A, Silva J, Gibbs P, Teixeira P (2009) Characterization for enterotoxin production, virulence factors, and antibiotic susceptibility of Staphylococcus aureus isolated from various foods in Portugal. Food Microbiol 26:278-282.

Rhayour K, Bouchikhi T, Tantaoui-Elaraki A, Sendide K, Remmal A (2003) The mechanism of bactericidal action of oregano and clove essential oils and of their phenolic major components. J Essent Oil Res 15:286-292.

Shah S, Stapleton PD, Taylor PW (2008) The polyphenol (-)-epicatechin gallate disrupts the secretion of virulence-related proteins by Staphylococcus aureus. Lett Appl Microbiol 46:181-185.

Shale K, Lues JFR, Venter P, Buys EM (2005) The distribution of Staphylococcus sp. on bovine meat from abattoir deboning rooms. Food Microbiol 22:433-438.

Souza EL, Stamford TLM, Lima EO (2006). Sensitivity of spoiling and pathogen-food related bacteria to Origanum vulgare L. (Lamiaceae) essential oil. Braz J Microbiol 37:527-532.

Souza EL, Stamford TLM, Lima EO, Trajano VN (2007) Effectiveness of Origanum vulgare L. essential oil to inhibit the growth of food spoiling yeasts. Food Cont 18:409-413.

Ultee A, Bennik MHJ, Moezelaar R (2002) The phenolic group of carvacrol is essential for action against the foodborne pathogen Bacillus cereus. Appl Environ Microbiol 68:161-1568.

Vanderzant C, Splittstoesser DF (1992) Compendium of methods for the microbiological examination of foods. American Public Health Association, Washington D.C., 1219 pp.

Walsh SE, Maillard JY, Russel AD, Catrenich CE, Charbonneau DL, Bartolo RG (2003) Activity and mechanism of action of selected biocidal agents on Gram-positive and negative bacteria. J Appl Microbiol 94:240-247.

All the content of the journal, except where otherwise noted, is licensed under a Creative Commons License CC BY-NC. 